\title{
Soluble Complex of Complement Increases Hydraulic Conductivity in Single Microvessels of Rat Lung
}

\author{
Shigemi Ishikawa, Hiroshi Tsukada, and Jahar Bhattacharya \\ Departments of Medicine and Physiology, College of Physicians and Surgeons, Columbia University, \\ St. Luke's-Roosevelt Hospital Center, New York 10019
}

\begin{abstract}
We determined the effect of sera enriched with the soluble complex of complement (SC5b-9), on hydraulic conductivity ( $L p$ ) of single pulmonary venules (diameter 20-30 $\mu \mathrm{m}$ ). Sera free of anticoagulants and blood cells were prepared from rat and human blood. Lp were determined by our split drop technique in isolated, blood-perfused lungs prepared from anesthetized rats ( 2\% halothane; Sprague Dawley, 500 g; $n=73$ ). Zymosan-activated (ZAS) and control sera were used for Lp determinations. In ZAS prepared from human serum, SC5b-9 concentration was $>300 \mu \mathrm{g} / \mathrm{ml}$ (control: $<1 \mu \mathrm{g} / \mathrm{ml}$ ) as determined by ELISA. At baseline, Lp averaged $3.4 \pm .4 \times 10^{-7} \mathrm{ml} /$ $\left(\mathrm{cm}^{2} \cdot \mathrm{s} \cdot \mathrm{cm} \mathrm{H} \mathrm{H}_{2} \mathrm{O}\right)$, but it increased by $217 \pm 32 \%$ with undiluted ZAS $(P<0.05)$. The $L p$ increase correlated significantly with different ZAS dilutions for rat serum and with SC5b-9 concentration for human serum. Lp did not increase significantly with ZAS prepared from heat-treated sera, C6- and C8-deficient sera; or with ZAS in which SC5b-9 had been depleted by immunoprecipitation. The ZAS-induced increase of $L_{p}$ was blocked completely by venular preinfusion with the arginineglycine-aspartic acid (RGD) tripeptide $(1 \mathrm{mg} / \mathrm{ml}, 10 \mathrm{~min}$ ). We report for the first time that: (a) SC5b-9 increases lung endothelial $L p$; and $(b)$ the increase of $L p$ is attributable to an integrin-dependent mechanism. (J. Clin. Invest. 1993.91:103109.) Key words: endothelium • permeability • immunology • vitronectin • integrin
\end{abstract}

\section{Introduction}

The terminal complement pathway synthesizes two end products: the soluble complex (SC5b-9) and the membrane attack complex (MAC). ${ }^{1}$ The soluble complex results from the binding of plasma vitronectin ( $\mathrm{VN}$ ) to complement proteins $\mathrm{C} 5 \mathrm{~b}$ through $\mathrm{C} 7$ to form SC5b-7, which then incorporates $\mathrm{C} 8$ and C9 to form SC5b-9 (1). MAC is synthesized when these complement protein complexes assemble on cell membrane instead of VN (1). Although the formation of these end products

Address correspondence to J. Bhattacharya, Roosevelt Hospital, Columbia University, 428 West 59th Street, New York, NY 10019.

Received for publication 20 April 1992 and in revised form 4 August 1992.

1. Abbreviations used in this paper: $\mathrm{CH}_{50}$, quantity of serum required to lyse $50 \%$ of red blood cells in a standard hemolytic complement assay; $\mathrm{J} v$, endothelial flux; $\mathrm{L} p$, hydraulic conductivity; MAC, membrane attack complex; $\mathrm{P} m v$, microvascular pressure; VN, vitronectin; ZAS, zymosan-activated serum.

J. Clin. Invest.

(C) The American Society for Clinical Investigation, Inc.

0021-9738/93/01/103/07 \$2.00

Volume 91, January 1993, 103-109 is expected after complement activation, their effects on endothelial permeability have received little attention (2). With regard to lung, previous studies of microvascular flux following complement activation have been dominated by the hemodynamic and neutrophil mediated effects of the anaphylatoxins - C3a, C5a, and C5a-des-Arg (3). Although more recent work indicates that terminal pathway products may cause pulmonary edema $(4,5)$, the extent to which the end products affect endothelial barrier properties remains poorly understood.

Here we have considered the microvascular effects of SC5b-9 which is plasma soluble and is likely to achieve high plasma levels following complement activation (6). The resultant exposure of microvascular beds in lung and other organs to SC5b-9 may cause significant permeability effects, hence it is important to understand whether SC5b-9 affects the endothelial barrier. There are at least three reasons for expecting such a permeability effect: ( $a$ ) SC5b-9 localizes at sites of endothelial injury (7-9); (b) an increase of plasma soluble complex levels predisposes to pulmonary edema (6);(c) SC5b-9 binds to endothelium through a VN-integrin interaction (10-12), and may thereby induce receptor-mediated permeability effects. SC5b-9's barrier effect may be quantified in terms of the endothelial hydraulic conductivity $(\mathrm{L} p)$ which we recently determined in single pulmonary microvessels, by means of our split drop procedure $(13,14)$. Using these methods we report for the first time, that serum enriched with SC5b-9 increased L $p$ in venules of rat lung.

\section{Methods}

Chemicals used

SOD (Sigma Chemical Co., St. Louis, MO); the arginine-glycineaspartic acid (RGD) tripeptide (Sigma Chemical Co.); purified human C6 (Quidel, San Diego, CA).

\section{Experimental sera}

Sera were prepared from rat and human blood. Heparin, which inhibits the terminal complement pathway (15), was avoided. Anticoagulantfree blood was collected by cardiac puncture in rats, and from the antecubital vein from healthy volunteers, then allowed to stand at $4^{\circ} \mathrm{C}$ for $1 \mathrm{~h}$. The layer of separated serum above the buffy layer was removed, centrifuged (5,000 $\mathrm{g} \times 10 \mathrm{~min}, \mathrm{RC} 2$-B; Sorvall Instruments Div. [part of DuPont Co.] Newtown, CT) then injected through a 0.8- $\mu \mathrm{m}$ filter (Millipore Co., Bedford, MA) to prepare cell-free serum. The absence of cells was confirmed by microscopic examination of the sera in a Neubauer chamber, as also in serum smears prepared on glass slides and stained with Wright's stain (magnification, 1,000). All sera were stored as separate aliquots in plastic containers at $-70^{\circ} \mathrm{C}$ and used within $4 \mathrm{wk}$ of preparation. For experiments, an aliquot was slowly warmed to $37^{\circ} \mathrm{C}$ by immersion in a constant temperature water bath (Lauda RC20; Fisher Scientific Co., Pittsburgh, PA). Each aliquot was thawed only once to avoid complement activation due to repeated thawing (9).

The rationale for inclusion of human serum in these studies was to enable use of commercially available human serum-specific products 
such as an ELISA kit for serum SC5b-9 quantitation and C6 and C8 deficient sera (see below). Rat serum was used in parallel, to control for heterologous effects.

The following special sera were prepared:

(a) Zymosan-activated serum (ZAS). To activate complement, serum was treated with zymosan (Sigma Chemical Co.) according to the method of Gawryl et al. (16). Zymosan was boiled ( $1 \mathrm{~h}$ ), cooled to room temperature with saline washes, then dissolved in serum at 10 $\mathrm{mg} / \mathrm{ml}$. After incubation of the mixture $\left(1 \mathrm{~h}\right.$ at $\left.37^{\circ} \mathrm{C}\right)$, the zymosan particles (diameter $3 \mu \mathrm{m}, 17$ ) were removed from the serum sample by centrifugation $(20,000 \mathrm{~g} \times 10 \mathrm{~min})$ followed by injection through a 0.8 $\mu \mathrm{m}$ filter.

(b) Nonactivated serum. Control serum was prepared in parallel to the ZAS procedures, except zymosan was not added.

(c) Heat-inactivated sera. To inactivate complement, rat sera were incubated at $56^{\circ} \mathrm{C}$ for 30 min before the ZAS preparation procedures.

(d) Complement-deficient sera. Human sera immunochemically depleted of complement fragments C6 and C8 were obtained from Quidel Inc. (San Diego, CA).

(e) C6-repleted ZAS. In one batch, C6-depleted serum was replenished with purified human C6 (Quidel) at $80 \mu \mathrm{g} / \mathrm{ml}$ which is the normal C6 concentration for human serum (18). The repleted serum was then zymosan activated.

(f) SC5b-9-depleted sera. SC5b-9 was depleted in ZAS by the immunoprecipitation method of Chenais et al. (19), using protein A. An anti-human SC5b-9 monoclonal antibody (Quidel) was added to freshly prepared ZAS at molar ratio $1: 1$ and incubated first $22^{\circ} \mathrm{C}(2 \mathrm{~h})$, then at $4^{\circ} \mathrm{C}(24 \mathrm{~h})$ while the samples were continuously rotated. Protein A-Sepharose CL4B gel (Sigma Chemical Co.; $1 \mathrm{ml}$ swollen gel binds $20 \mathrm{mg} \mathrm{IgG}$ ) was added to the mixture and incubated for $3 \mathrm{~h}$ at $22^{\circ} \mathrm{C}$ with constant rotation of samples. Substrate-bound immunecomplexes were removed from serum by centrifugation $(3,000 \mathrm{~g} \times 10$ $\mathrm{min}$ ) and filtration $(0.8 \mu \mathrm{m})$. Sham samples of serum were prepared by identical methods except antibody was not added. SC 5 b- 9 was quantified by ELISA in the treated sera.

Serum analyses. In each serum sample we determined protein oncotic pressure by membrane osmometry (osmometer, model 4100 ; Wescor Inc., Logan, UT), total protein concentration by the biuret method (20) (spectrophotometer, model 6/20; Coleman, Maywood, IL) and osmolality by freezing point depression (The Advanced Micro-Osmometer, model 3M0; Advanced Instruments, Inc., Needham Height, MA). In all samples, endotoxin levels were undetectable by limulus assay (limulus assay kit; Sigma Chemical Co.).

For human serum, in one batch each of control, zymosan-activated, SC5b-9-depleted, and C6-deficient sera, we determined SC5b-9 level by an ELISA kit (Quidel). In addition, we assayed functional hemolytic complement activity in these samples as the quantity or dilution of serum required to lyse $50 \%$ of the red blood cells in a standard hemolytic complement assay $\left(\mathrm{CH}_{50}\right)(21)$.

\section{Experimental procedures}

Lung preparation. The isolated, blood-perfused rat lung was set up according to our standard procedures which we have described in detail (14). Briefly, in each experiment lungs were removed from one anesthetized rat (500-600 g; halothane $2 \%$ inhalation followed by sodium pentobarbital $40 \mathrm{mg} / \mathrm{kg}$, intraperitoneal; Harlan Sprague-Dawley, Inc., Indianapolis, IN). Then the lung was cannulated at the pulmonary artery, left atrium, and trachea, and immediately pump perfused in a perfusion circuit with blood drawn by cardiac puncture from a second rat. The perfusion blood was heparinized ( $500 \mathrm{U})$ and diluted with $4 \mathrm{~g} \%$ albumin (rat albumin, Fraction V; Sigma Chemical Co.) in Ringer's lactate, to achieve hematocrit of $20 \%$. The lungs were inflated with gas $\left(30 \% \mathrm{O}_{2}, 6 \% \mathrm{CO}_{2}, 64 \% \mathrm{~N}_{2}\right)$ to maintain blood $\mathrm{PO}_{2}, \mathrm{PCO}_{2}$, and $\mathrm{pH}$ at, respectively, 140 Torr, 35 Torr, and $7.3 \mathrm{pH}$ units; as determined every 30 min ( 178 pH/Blood Gas Analyzer; Corning Glass Inc., Corning, NY). A heat exchanger maintained perfusate temperature (44TD; Yellow Springs Instrument Co., Yellow Springs, $\mathrm{OH}$ ) at $37^{\circ} \mathrm{C}$.

Lung vascular pressures were regulated by adjusting the height of the venous outflow. Opening a shunt between the arterial and the venous cannulae, stopped lung blood flow during the split drop procedure. Pressure transducers (P23 ID; Gould Statham, Oxnard, CA) recorded large vessel pressures with respect to the micropuncture level Airway pressure was held constant at $5 \mathrm{~cm} \mathrm{H}_{2} \mathrm{O}$ during micropuncture, but cyclically varied to induce ventilation during nonmicropuncture intervals lasting 10-15 min. Pressure recordings were displayed on a multichannel recorder (RS 3400; Gould Statham).

\section{Preparative procedures for lung micropuncture}

The micropuncture surface. The diaphragmatic or costal lung surface was positioned on a vibration free air table (Micro-G; Technical Manufacturing Corp., Woburn, MA) for stereomicroscopy $(\times 150$; Olympus model SZH), videoimaging (Panasonic WV-5410), and videorecording (Panasonic AG-6050) by means of a closed circuit TV system (Panasonic CCTV; camera WV-CD51). The micropuncture surface was layered with silicone oil (200; Dow Corning Corp., Midland, MI) at $37^{\circ} \mathrm{C}$ (Thermalert TH-5; Sensortek, Clifton, NJ). The lung elsewhere was covered by plastic wrap (Saran Wrap).

Micropipettes. Micropipettes (tip diameter $\sim 5 \mu \mathrm{m}$ ) were pulled (Sachs-Flaming Puller, model P-84; Sutter Instrument Co., Novato, $\mathrm{CO}$ ) and bevelled (Sutter Instrument Co. beveller) from glass tubing ( 1 mm diameter; Glass Co. of America, Millville, NJ) which had been acid cleaned, sterilized, and siliconized. They were filled with either castor oil colored with carbon black B or the experimental serum ("split solution").

\section{Split drop procedures}

Venules (diameter $20-25 \mu \mathrm{m}$ ) were identified by noting the distribution pattern expected for venular blood flow $(13,14)$. The micropuncture steps of our split drop procedure are illustrated in Fig. 1. After stopping lung blood flow at vascular pressure of $5 \mathrm{cmH}_{2} \mathrm{O}$, the experimental venule was micropunctured with the oil pipette to inject $\sim 100-200 \mu \mathrm{m}$ of vessel length with oil. The serum pipette was then used to split the oil drop with an injection of the test serum (split solution) to separate the margins of the split oil drop by $\sim 80 \mu \mathrm{m}$. In the third step, more oil was injected through the oil pipette to displace the split drop $\sim 40 \mu \mathrm{m}$ away from the micropuncture sites. This crucial step ensured placement of the experimental solution in a nonmicropunctured region of the vessel, hence leaks through micropuncture defects were prevented. Finally, both micropipettes were removed. We rejected split drop data if step 3 (Fig. 1 ) of the procedure was unsuccessful and if blood entered the split drop.

Every $10 \mathrm{~s}$ ( videotimer: VTG-33; FOR-A Corp. of America, Newton, MA), microvessel diameter and minimum distance between the split drop margins ( split drop length) were determined by microcaliper (Mitutoyo Corp., Tokyo, Japan), from a frame-by-frame replay of the videorecording $(\times 400$; resolution $1 \mu \mathrm{m})$. Split drop length decreased with liquid exit from the split drop (filtration), but increased with liquid entry (absorption). Microvessel diameter remained constant. We estimated liquid flux per unit surface area $(\mathrm{J} v)$ at time zero according to our analysis described fully in previous reports $(13,14)$. Briefly, split drop length and diameter data were used in the cylinder formula to calculate split drop volume and surface area. Then $\mathrm{J} v$ was calculated by differentiating at time zero, the slope of the exponential regression of split drop volume versus time in the first minute. The split solution maintained endothelial contact for $<2 \mathrm{~min}$. The linear $\mathrm{J} v$-microvascular pressure ( $\mathrm{P} m v$ ) relation was determined through $\mathrm{J} v$ measurements at different $\mathrm{P} m v$. The line's slope gave $\mathrm{L} p(13,14)$.

We have established that in this preparation, $L p$ remains, unchanged for up to $4 \mathrm{~h}$ (14). Therefore we completed all split drop determinations within this period. We have also established that large vessel pressures (e.g., pulmonary artery) are identical to split drop hydrostatic pressures (13), that neither our micropuncture procedures nor the endothelial contact with oil deteriorates the endothelial barrier, and that the $\mathrm{J} v-\mathrm{P} m v$ line is highly correlated by linear regression (14). Based on our previous micropuncture measurements $(14,22)$, we assumed perivenular interstitial pressure to be $0 \mathrm{~cm} \mathrm{H}_{2} \mathrm{O}$ (13). After the experiment, the lung was homogenized for determination of extravas- 

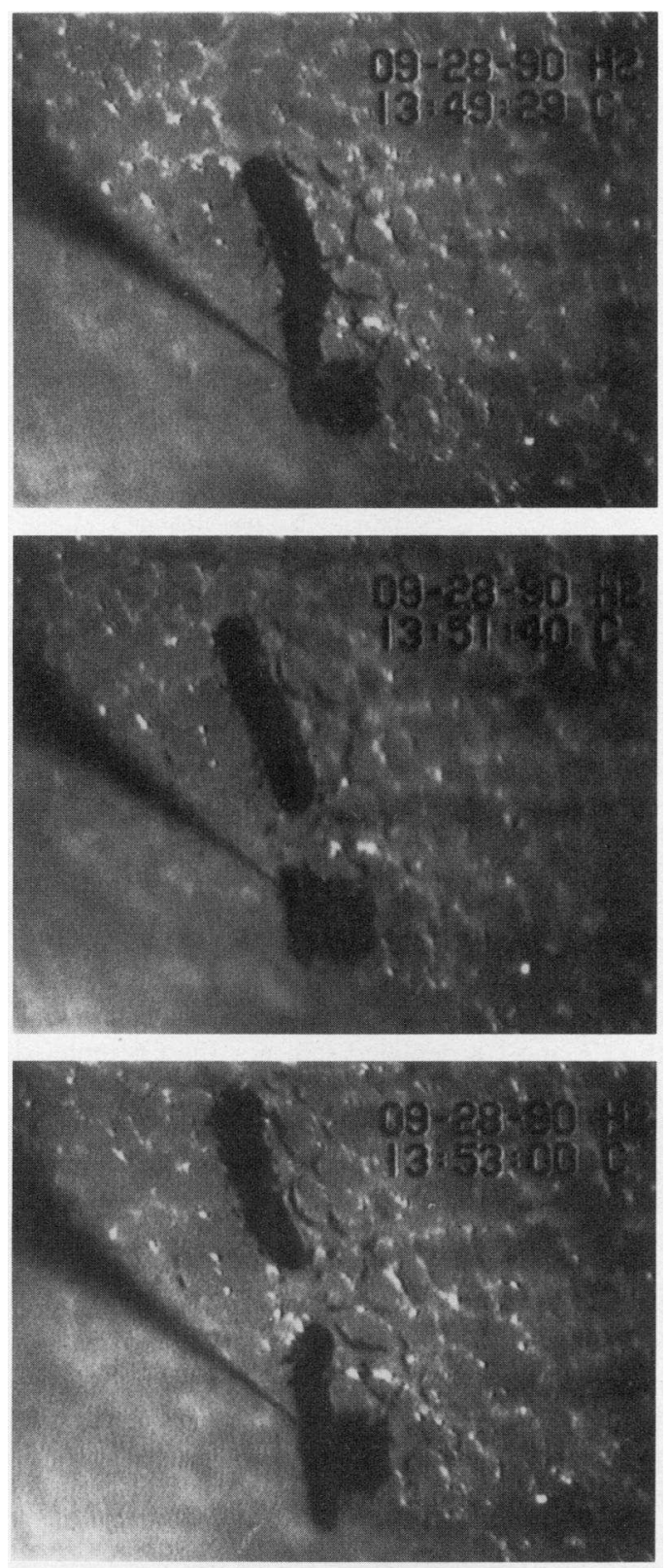

Figure 1. Sequential steps of split drop procedure. Frames show videorecordings of a pulmonary venule (diameter $30 \mu \mathrm{m}$ ). (Upper panel) The venule has been micropunctured and filled with castor oil stained with Sudan black. The oil pipette is visible on left. (Middle panel) The oil drop has been split by an injection of serum through a second pipette. The serum was colorless, hence the second pipette is not visible in the photograph. The micropuncture site of the second pipette is located at the bottom margin of the split segment. (Lower panel) By additional oil injections the segment containing serum has been displaced above both micropuncture sites. This step prevents leakage of experimental serum through micropuncture defects in the vessel wall. Before flux determination, both pipettes were withdrawn.

cular lung water content by our standard procedures $(13,22)$. Data were rejected if lung water exceeded $4 \mathrm{~g} / \mathrm{g}$ dry.

\section{Experimental Groups}

$L_{p}$ responses to different dilutions of ZAS (rat sera). ZAS was used either undiluted or in dilutions with nonactivated serum as 50,20 , and $10 \%$ solutions. In each experiment, paired, control measurements of
L $p$ were obtained using nonactivated serum. In one group, ZAS was prepared with heat-treated serum.

Complement-deficient experiments (human sera). In these experiments, we determined SC5b-9 concentrations by ELISA. In separate groups, $\mathrm{L} p$ responses to ZAS were compared against responses for, respectively, ZAS prepared with C6 and C8 deficient sera, SC5b-9-depleted ZAS, and C6-repleted ZAS. In another group, we used a $10 \%$ $\mathrm{vol} / \mathrm{vol}$ dilution of ZAS in nonactivated serum.

Preinfusion experiments (rat sera). We microinfused venules for $10 \mathrm{~min}$ with the arginine-glycine-aspartic acid (RGD) tripeptide dissolved in $4 \mathrm{~g} \%$ albumin at a concentration of $1 \mathrm{mg} / \mathrm{ml}(23)$, then immediately followed with the split drop procedure using ZAS as split solution. Control $\mathrm{L} p$ were determined in venules which were both nonpreinfused, and in which preinfusions were carried out with only the vehicle, $4 \mathrm{~g} \%$ albumin. The rationale for using $4 \mathrm{~g} \%$ albumin was that a sufficiently high oncotic pressure was required to prevent rapid solution escape into the interstitium. To further prevent such escape during

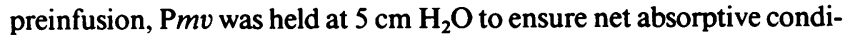
tions $(13,14)$.

Statistics. Data are presented as mean \pm SE. Paired differences were tested by the paired $t$ test, and differences among more than 2 groups by the ANOVA-Neuman Keul's test. Significance was accepted at $P$ $<0.05$.

\section{Results}

Effect of $Z A S$. The plots shown in Fig. 2 for a single experiment, represent $\mathrm{J} v$-P $m v$ relationships that were obtained using ZAS and control serum as split solutions. The slope of the relationship gave $\mathrm{L} p$. In this experiment, $\mathrm{L} p$ was $3.4 \times 10^{-7}$ $\mathrm{ml} /\left(\mathrm{cm}^{2} \cdot \mathrm{s} \cdot \mathrm{cm} \mathrm{H}_{2} \mathrm{O}\right)$ for control serum, but it increased to 9.5 with ZAS.

ZAS prepared from fresh serum always increased $\mathrm{L} p$. These $\mathrm{L} p$ responses to ZAS were assessed in different groups. In three groups, ZAS was diluted by addition of control serum as indicated (Table I). In a fourth group, undiluted ZAS was used. In each group, $\mathrm{L} p$ responses were determined as paired comparisons of ZAS against control serum (Table I). The overall average for $\mathrm{L} p$ from the 20 baseline determinations, was $3.4 \pm .4 \times 10^{-7} \mathrm{ml} /\left(\mathrm{cm}^{2} \cdot \mathrm{s} \cdot \mathrm{cm} \mathrm{H}_{2} \mathrm{O}\right)$. In each group, ZAS always increased $\mathrm{L} p$ above baseline. This effect was most pronounced in the undiluted group, in which $\mathrm{L} p$ increased on average by $217 \pm 32 \%$. However as evident from the SE of the experimental groups in Table $\mathrm{I}$, the $\mathrm{L} p$ increases varied between experiments. As shown in Fig. 3, the means of the $\mathrm{L} p$

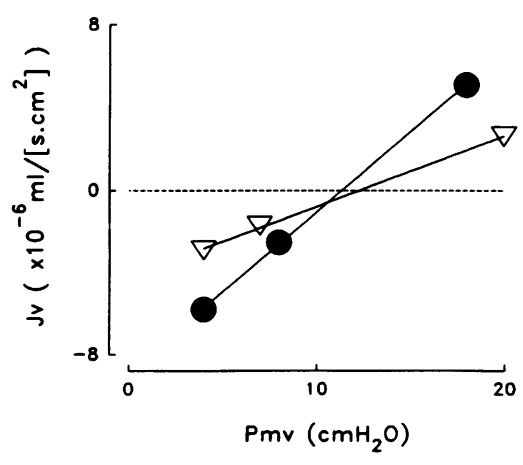

Figure 2. Plots of endothelial flux $(\mathrm{J} v)$ versus microvascular pressure $(\mathrm{P} m v)$ from one experiment. $\mathrm{J} v$ was determined in single venules using serum as split solution. Slopes determined by linear regression $(P<0.05$ for both $)$ gave endothelial hydraulic conductivity $(\mathrm{L} p)$. $\mathrm{L} p$ for zymosan activated serum was 2.8 times higher than baseline $\mathrm{L} p$ determined with nonactivated serum $\left(3.4 \times 10^{-7} \mathrm{ml} /\left[\mathrm{cm}^{2} \cdot \mathrm{s} \cdot \mathrm{cm} \mathrm{H}_{2} \mathrm{O}\right]\right)$. Rat serum: $\nabla$, baseline; $\bullet, \mathrm{zy}-$ mosan activated. 
Table I. $L_{p}$ Determined with Different Dilutions of ZAS

\begin{tabular}{ccc}
\hline & \multicolumn{2}{c}{$\mathrm{L}_{p}\left(\times 10^{-7} \mathrm{ml} /\left(\mathrm{cm}^{2} \cdot \mathrm{s} \cdot \mathrm{cm} \mathrm{H}_{2} \mathrm{O}\right)\right.$} \\
\cline { 2 - 3 } ZAS dilutions & Control & Experimental \\
\hline vol/vol \% & & \\
10 & $3.5 \pm .8$ & $6.4 \pm .9^{*}$ \\
20 & $3.8 \pm 1$ & $7.2 \pm 1.4^{*}$ \\
50 & $2.9 \pm .4$ & $7.7 \pm 1.1^{*}$ \\
100 & $3.4 \pm .7$ & $10.5 \pm 2^{*}$
\end{tabular}

Mean \pm SE; $n=5$ for each group; ZAS, zymosan-treated serum; $\mathrm{L}_{p}$, hydraulic conductivity; vol/vol \%, percent ZAS in nonactivated serum; ${ }^{*} P<0.05$ compared with control.

increases correlated linearly with $\log$ dilution of ZAS $(P<0.05$ by linear regression).

In these 20 experiments, the extravascular water contents of experimental and control lungs were not significantly different $(3.6 \pm .2$ versus $3.6 \pm .1 \mathrm{~g} / \mathrm{g}$ dry $)$. Therefore our procedures did not cause pulmonary edema.

Heat treatment of serum completely abolished the $\mathrm{L} p$ response to ZAS. In four experiments, $\mathrm{L} p$ determined with ZAS prepared from heat-treated serum $\left(3.5 \pm .4 \times 10^{-7} \mathrm{ml} /\right.$ $\left.\left[\mathrm{cm}^{2} \cdot \mathrm{s} \cdot \mathrm{cm} \mathrm{H} \mathrm{H}_{2} \mathrm{O}\right]\right)$ was not significantly different from baseline $\left(3.2 \pm .2 \times 10^{-7} \mathrm{ml} /\left[\mathrm{cm}^{2} \cdot \mathrm{s} \cdot \mathrm{cm} \mathrm{H}_{2} \mathrm{O}\right]\right)$. In contrast, in five concurrent experiments, ZAS prepared as usual significantly increased $\mathrm{L} p$ above baseline (respective $\mathrm{L} p$ for $\mathrm{ZAS}$ and baseline: $10.5 \pm 2$ and $\left.3.4 \pm .7 \times 10^{-7} \mathrm{ml} /\left[\mathrm{cm}^{2} \cdot \mathrm{s} \cdot \mathrm{cm} \mathrm{H}_{2} \mathrm{O}\right]\right)$.

Addition of SOD did not affect $\mathrm{L} p$. In four experiments, we added $200 \mathrm{U} / \mathrm{ml}$ of SOD into both the perfusate and the aliquot of ZAS used as split solution. The mean L $p$ obtained with a split solution mixture of ZAS and SOD was $7.5 \times 10^{-7}$ $\mathrm{ml} /\left(\mathrm{cm}^{2} \cdot \mathrm{s} \cdot \mathrm{cm} \mathrm{H}_{2} \mathrm{O}\right)$. This was similar to the paired value obtained with ZAS without SOD $\left(8.1 \times 10^{-7} \mathrm{ml} /\right.$ $\left[\mathrm{cm}^{2} \cdot \mathrm{s} \cdot \mathrm{cm} \mathrm{H}_{2} \mathrm{O}\right]$ ).

Complement-deficient experiments. We detected no differences in $\mathrm{L} p$ determined with human and rat sera. Both the baseline $\mathrm{L} p\left(3 \pm .6 \times 10^{-7} \mathrm{ml} /\left[\mathrm{cm}^{2} \cdot \mathrm{s} \cdot \mathrm{cm} \mathrm{H}_{2} \mathrm{O}\right], n=8\right)$ as also the $\mathrm{L} p$ response to ZAS (Fig. 4, left extreme filled bar) did not significantly differ from the corresponding data for rat serum (NS by ANOVA-Neuman Keul's test).

Our ELISA determinations in six batches of human serum are summarized in Table II. In control serum, SC5b-9 was $<1$ $\mu \mathrm{g} / \mathrm{ml}$, as consistent with previous reports (24). The control

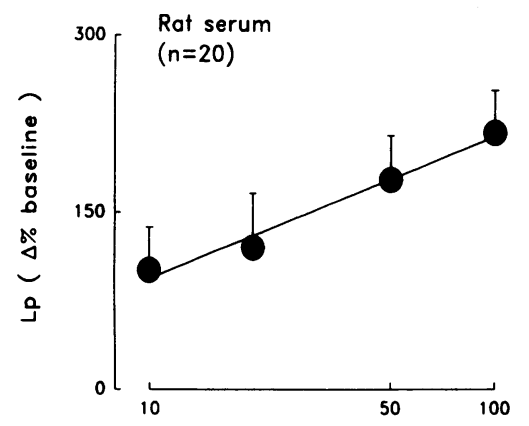

Fractional volume of activated serum in split solution ( $\%$ )

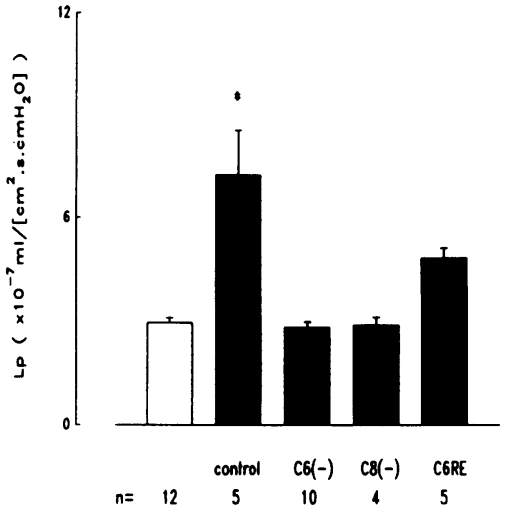

Figure 4. The effects of complement depleted sera (mean \pm SE for human sera; ${ }^{*} P<0.05$ by ANOVA-Neuman Keul's). Zymosan activation of control sera increased $\mathrm{L} p$ above baseline. However, activation of $\mathrm{C} 6(\mathrm{C} 6(-))$ and $\mathrm{C} 8(\mathrm{C} 8(-))$-depleted sera did not affect Lp. C6 repletion followed by activation (C6RE) increased $\mathrm{L} p$.

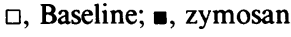
activated.

ZAS sample was markedly SC5b-9 enriched. However, after immunoprecipitation, ZAS was depleted of SC5b-9. As expected, SC5b-9 was undetectable in ZAS prepared with $\mathrm{C} 6$ and C8 deficient sera obtained commercially (data not shown). When we repleted $\mathrm{C} 6$ deficient serum with purified C6, zymosan activation increased serum SC5b-9 concentration. However this increase was considerably less than the increase of SC5b-9 concentration achieved in fresh serum. The discrepancy may be attributable to low levels of other complement factors in the commercially prepared C6 deficient serum.

Neither the $\mathrm{C} 6$ and $\mathrm{C} 8$ depleted sera nor the $\mathrm{C} 6$ repleted serum affected baseline $\mathrm{L} p$ under nonactivated conditions (data not shown). Although ZAS prepared with fresh serum increased $\mathrm{L} p$ as usual, ZAS prepared with C6-deficient or C8-deficient sera failed to increase L $p$ above baseline (Fig. 4). Using ZAS prepared with the C6-repleted serum, we recovered $49.7 \pm 5.7 \%$ of the control $\mathrm{L} p$ response to ZAS. ZAS that had been sham immunoprecipitated as usual markedly increased $\mathrm{L} p\left(6.5 \pm .4 \times 10^{-7} \mathrm{ml} /\left[\mathrm{cm}^{2} \cdot \mathrm{s} \cdot \mathrm{cm} \mathrm{H} \mathrm{H}_{2} \mathrm{O}\right]\right)(P<0.05)$. However, ZAS that had been SC $5 \mathrm{~b}-9$ depleted, failed to increase $\mathrm{L} p$ above baseline. Thus, with SC5b-9-depleted ZAS, L $p$ was $2.7 \pm .3 \times 10^{-7} \mathrm{ml} /\left(\mathrm{cm}^{2} \cdot \mathrm{s} \cdot \mathrm{cm} \mathrm{H}_{2} \mathrm{O}\right)$, which was not significantly different from baseline (compared by ANOVA-Neuman Keul's against baseline $\mathrm{L} p$ of other groups).

In Fig. 5 we have plotted the mean $\mathrm{L} p$ determined for each serum type against the log of the corresponding serum SC5b-9

Table II. Serum ELISA for SC5b-9

\begin{tabular}{lc}
\hline \multicolumn{1}{c}{ Serum } & SC5b-9 \\
\hline & $\mu g / m l$ \\
Control & $<1$ \\
ZAS & 333 \\
ZAS-SC5b-9(-) (Sham) & 525 \\
ZAS-SC5b-9(-) & 7 \\
ZAS-C6(RE) & 16 \\
ZAS 10\% & 28 \\
\hline
\end{tabular}

ELISA with monoclonal antibody to SC5b-9 (Quidel Inc.); ZAS, zymosan-treated serum; ZAS-SC5b-9(-), ZAS depleted of SC5b-9; ZAS-C6(RE), ZAS prepared with C6-repleted serum; ZAS 10\%, 10\% dilution of ZAS in control serum. 


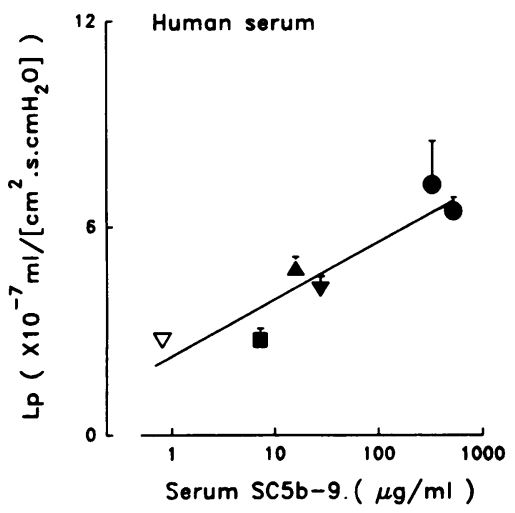

Figure 5. Effect of SC5b-9 concentration on $\mathrm{L} p$. Mean $( \pm \mathrm{SE}) \mathrm{L} p$ for different batches of serum have been plotted against corresponding SC5b-9 concentrations determined by ELISA. The sera batches are: nonactivated serum (open inverse triangle, $n$ $=8$ ), zymosan-activated serum immunodepleted of SC5b-9 (filled square, $n=5$ ),

C6-repleted serum (filled regular triangle, $n=5$ ), $10 \% \mathrm{vol} / \mathrm{vol}$ dilution of zymosan-activated serum in control serum (filled inverse triangle, $n=4$ ) and two batches of zymosan-activated serum (filled circles, $n=5$ each ). $\mathrm{L}_{p}$ correlated linearly with $\log$ SC5b-9 concentration $(P<0.05$ by linear regression $)$.

concentration from Table II. The plot correlated significantly by linear regression indicating an exponential relationship. An analysis of variance amongst the six serum groups indicated that $\mathrm{L} p$ was significantly higher than baseline for all groups, except for the immunoprecipitated group $(P<0.05$ by ANOVA-Neuman Keul's test).

In nonactivated human serum, we detected a $\mathrm{CH}_{50}$ score of $24 \mathrm{U} / \mathrm{ml}$ which is within normal limits (21). However, in $\mathrm{ZAS}, \mathrm{a} \mathrm{CH}_{50}$ score was undetectable $(<5 \mathrm{U} / \mathrm{ml})$. This indicates that zymosan activation resulted in complete consumption of serum complement.

Fig. 6 summarizes results of the microinfusion experiments. As before, ZAS markedly increased $\mathrm{L} p$ above baseline by similar extents in both noninfused venules and venules infused with only vehicle ( $4 \mathrm{~g} \%$ albumin $)(P<0.05)$. In contrast, in venules preinfused with the RGD tripeptide, ZAS failed to increase $\mathrm{L} p$ above baseline (NS). $\mathrm{L} p$ determined with control serum after microinfusions of RGD alone, did not differ from baseline $\left(3.3 \pm .1 \times 10^{-7} \mathrm{ml} /\left[\mathrm{cm}^{2} \cdot \mathrm{s} \cdot \mathrm{cm} \mathrm{H}_{2} \mathrm{O}\right], n=5\right)$.

\section{Discussion}

We demonstrate for the first time that in single pulmonary microvessels complement-activated serum increased $L p$ by a

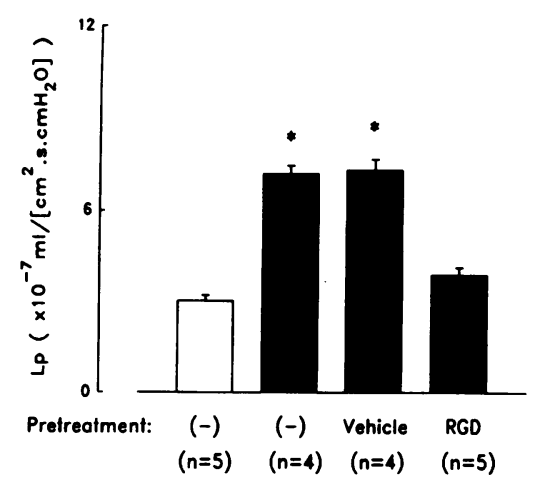

Figure 6. The effect of the RGD (ARG-GLYASP) tripeptide on $\mathrm{L} p$ (means $\pm \mathrm{SE} ;{ }^{*} P<0.05$ compared with baseline). Baseline determined with nonactivated serum in noninfused $(-)$ venules. ZAS increased $\mathrm{L} p$ identically in noninfused and vehicle ( $4 \mathrm{~g} \%$ albumin) preinfused venules. After RGD ( $1 \mathrm{mg} / \mathrm{ml})$ preinfusion, ZAS failed

to increase $\mathrm{L}_{p}$ above baseline. Rat serum: $\square$, baseline; $a$, zymosan activated. direct effect that was white blood cell independent and that occurred within $1 \mathrm{~min}$. The response was attributable to a heatlabile complement product, because we inhibited the $L p$ increase using sera which were heat treated or deficient in C6 or C8. This $\mathrm{C} 8$ dependence indicates that the product was formed in the post $\mathrm{C} 8$, terminal phase of complement activation. Post $\mathrm{C} 8$ products include the $\mathrm{VN}$-incorporated soluble complexes (SC5b-8 and SC5b-9) and MAC. Although all of these products may form in the terminal phase, we have three principal reasons for believing that our results were not attributable to MAC. First, we ensured that all sera were cell free; hence, no membranes were available for MAC formation during zymosan activation. Second, our $\mathrm{CH}_{50}$ determinations indicate that complement was completely consumed in sera activated with zymosan. Therefore ZAS was free of MAC precursors and MAC could not have formed when we microinjected ZAS into the experimental venule. Third, we inhibited the $\mathrm{L} p$ response to ZAS by pretreating venules with the RGD tripeptide. This result rules out the involvement of MAC which acts directly on the membrane rather than through RGD recognition (25). Therefore our $\mathrm{L} p$ findings were attributable to a soluble product. Since complement was completely consumed in our samples of ZAS, the terminal complement pathway proceeded to completion. Hence we interpret that the soluble product was SC5b-9.

Our ability to inhibit the present $\mathrm{L} p$ increase by RGD pretreatment implicates an integrin-based mechanism in the response to ZAS. This possibility is supported by the presence of VN in SC5b-9. The RGD sequence of VN recognizes an endothelial integrin $(10,14,26)$, and pretreatment of the integrin receptor with RGD inhibits the recognition $(23,27)$. An RGD based interaction between $\mathrm{VN}$ and a cell surface integrin has been implicated in the adherence of SC5b-9 to cultured myoblasts (28). Although the $\alpha_{v} \beta_{3}$ integrin is believed to be the endothelial receptor for $\mathrm{VN}(29)$, the involvement of this integrin in the present responses remains uncertain. Lampugnani et al. recently demonstrated that application of RGD to cultured endothelial monolayers induced the formation of large intercellular gaps (30). This effect was attributed to inhibition of the fibronectin-dependent intercellular adhesion which stabilizes the cultured monolayer. We were unable to confirm this finding because in our experiments with control serum RGD pretreatment did not detectably alter $\mathrm{L} p$ from untreated baseline values. This difference from the findings of Lampugnani et al. may be attributable to intrinsic differences of barrier properties between intact and cultured endothelium. We affirm that RGD pretreatment does not affect baseline barrier conductance; but the fact that it inhibits the $\mathrm{L} p$ response to ZAS indicates that endothelial integrins may subserve a barrier regulatory function.

In activated human serum, we quantified SC $5 b-9$ by means of a recently described sandwich ELISA (9) for which a kit is commercially available. Although this ELISA is based on a monoclonal antibody that recognizes both SC5b-9 and MAC, in cell-free serum only SC5b-9 is assayed $(9,31)$. We confirm that serum SC5b-9 concentration is normally negligible (6), and that it increases to $>300 \mu \mathrm{g} / \mathrm{ml}$ after zymosan activation (16). Although immunodepletion of SC5b-9 abolished the $\mathrm{L} p$ response to ZAS, the log concentration of SC5b-9 correlated linearly with $\mathrm{L} p$ increases. Because of this exponential relationship, small increases of SC5b-9 concentration did not signif- 
cantly increase $\mathrm{L} p$. For instance, when we depleted SC5b-9 in ZAS by immunoprecipitation, the resulting SC $5 b-9$ concentration was $7 \mu \mathrm{g} / \mathrm{ml}$ ( Table II). Although this concentration was higher than control $(<1 \mu \mathrm{g} / \mathrm{ml})$, it did not detectably increase $\mathrm{L} p$. An ELISA kit is not available for rat serum in which we therefore did not assay SC5b-9. However, we point out that similar increases of $\mathrm{L} p$ occurred with activated sera from both rat and human sources, and that different dilutions of activated rat sera also correlated nonlinearly with $\mathrm{L} p$. The similarity in the $\mathrm{L} p$ responses to rat and human sera indicate that heterologous effects did not blunt the interaction of human SC5b-9 with rat endothelium. The concentration-dependent responses from rat and human sera are consistent with clinical reports that high (6) but not low (32) levels of serum-soluble complex predispose to barrier pathology. The abolition of the $\mathrm{L} p$ response after immunodepletion of SC5b-9 and the concentration dependence of the $\mathrm{L} p$ response (Fig. 5), also support our view that SC5b-9 was the critical factor in the present barrier response.

Although many previous reports have examined the effect of complement activation on lung liquid balance (recently reviewed in $2,3,33$ ), ours is the first to quantitate the direct barrier effect of a terminal complement product. In previous studies, complement was activated either in the airway or in the circulation $(2,3,33,34)$. The resulting lung microvascular flux responses were attributed to the effects of neutrophil activation and pulmonary hemodynamic changes caused by the anaphylatoxins C3a, C5a, and C5a-des-Arg (3, 33). Seeger et al. attributed an increase of filtration coefficient in rabbit lungs given human serum, to a Forssman type reaction (26). Their response, which occurred with a $>30$ min delay, is clearly different from ours in which $\mathrm{L} p$ increased within $1 \mathrm{~min}$.

Our principal aim here was to quantify endothelial barrier properties in terms of $\mathrm{L} p$ in single lung microvessels exposed to SC5b-9-enriched serum. We took advantage of the fact that in the absence of cell membranes and heparin, serum complement activation causes pure SC5b-9 formation (9). We chose the single microvessel approach which by our recently developed methods allows accurate determinations of $\operatorname{Lp}(13,14)$. We recognize that single vessel data must be interpreted with caution with regard to the whole organ. However, our approach afforded several advantages. The L $p$ determination was precise because our approach uniquely makes possible in situ estimates of the critical surface area of filtration in the observed microvessel $(1,12,13)$. We avoided interference from hemodynamic factors which have traditionally complicated permeability interpretations in lung.

In interpreting our data, we considered possible leukocyte effects. Although lung resident leukocytes have been shown to localize in alveolar septal capillaries which are two vascular generations upstream of our experimental venules (35), marginating leukocytes may have been resident in the split drop segment of the venule. Such leukocytes could have been activated by complement-activated sera and thereby could have induced independently oxidative damage to the venular endothelium $(3,33)$. However, we have three reasons for believing that leukocyte activation did not affect the present $\mathrm{L} p$ responses: $(a)$ leukocyte-generated oxidative effects occur independently of RGD recognition mechanisms. Therefore, our ability to inhibit completely the $\mathrm{L} p$ response to ZAS with RGD pretreatment strongly argues against leukocyte activation as being a mechanism for the increase of $\mathrm{L} p .(b)$ Leukocyte activation is expected to induce SOD inhibitible oxidative damage. However, in four experiments, when we added SOD at a dose sufficient to inhibit a possible toxic radical effect attributable to leukocyte activation, the $\mathrm{L} p$ response to ZAS was not affected. (c) Anaphylatoxins such as C5a are strong activators of leukocytes $(3,33)$. Although anaphylatoxins were probably formed in zymosan activated sera which were, respectively, C6, C8, and SC5b-9-deficient, none of these sera increased L $p$ significantly. Therefore, either the venules were leukocyte free or the leukocyte activation was not sufficient to evoke $\mathrm{L} p$ changes in the 1-min experimental period. Moreover, because of its large size $(\mathrm{kD}>900 ; 1)$, it is unlikely that the SC 5b-9 complex was transported across the endothelium within the response time of $1 \mathrm{~min}$, to activate leukocytes lying in the perivenular interstitium. Taken together, these considerations rule out the importance of leukocyte activation as being a significant factor in our experiments.

Because our single microvessel technique is relatively new, some procedural considerations may be relevant. We determined $\mathrm{L} p$ on the established principle that when $\mathrm{J} v$ relates linearly to $\mathrm{P} m v$, the slope equals $\mathrm{L} p(14,36)$. Here and previously we demonstrated that the $\mathrm{J} v$-P $m v$ relation determined with three or more points gives a highly correlated linear relationship with positive slope (14). We have also established that the luminal hydrostatic pressure in the split drop equals large vessel pressures during stop flow conditions (13), that the oilendothelial contact and the double micropuncture procedure do not detectably damage the endothelial barrier (14), and that oil viscosity is not a significant factor in the estimation of $\mathrm{J} v$ (unpublished observations). Therefore we do not believe that our procedures affected the present data. As compared with the present baseline $\mathrm{L} p$ for serum, previously we reported a higher baseline $\mathrm{L} p$ for albumin solution $\left(5.5 \times 10^{-7} \mathrm{ml} /\left[\mathrm{cm}^{2} \cdot \mathrm{s} \cdot \mathrm{cm}\right.\right.$ $\left.\mathrm{H}_{2} \mathrm{O}\right]$ ). This difference may be attributable to the known barrier-enhancing properties of serum (37).

In conclusion, our results indicate for the first time that SC5b-9-enriched sera rapidly increased L $p$ of single lung microvessels. This response demonstrates that SC5b-9 affects the endothelial barrier, hence it questions the prevalent notion that the sole biological function of SC5b-9 is to prevent the lytic effects of MAC $(1,25)$. Since the $\mathrm{L} p$ increase was RGD inhibitible, we report the first evidence of an integrin-dependent regulation of the endothelial barrier. These new findings raise the significant possibility that SC5b-9 through a blood-borne effect, may diminish the lung endothelial barrier even when complement activation is extrapulmonary.

\section{Acknowledgments}

We thank Drs. Y. Inada and E. Rivkin for help with ELISA and immunoprecipitation procedures, and Ms. R. Patel for technical assistance. Dr. R. Sadurski assisted in manuscript preparation and Dr. P. R. B. Caldwell reviewed the manuscript.

This work was supported by grant HL-36024 from the National Institutes of Health, and a grant-in-aid to J. Bhattacharya from the American Heart Association.

\section{References}

1. Law, S. K. A., and K. M. B. Reid. 1988. In Complement. D. Male, editor. IRL Press, Washington, DC. 9--28.

2. Warren, J. S., K. J. Johnson, and P. A. Ward. 1991. Immunoglobulin- and 
complement-mediated immune injury. In The Lung: Scientific Foundations. R. G. Crystal and J. B. West, editors. Raven Press, Ltd., NY. 1939-1946.

3. Flick, M. R. 1988. Pulmonary edema and acute lung injury. In Textbook of Respiratory Medicine. J. F. Murray and J. A. Nadel, editors. W. B. Saunders Co., Philadelphia, PA. 1359-1409.

4. Camussi, G. E., P. R. B. Caldwell, G. Andres, and J. R. Brentjens. 1987. Lung injury mediated by antibodies to endothelium. Am. J. Pathol. 127:216-228.

5. Seeger, W., R. Hartmann, H. Neuhoff, and S. Bhakdi. 1989. Local complement activation, thoromboxane-mediated vasconstriction, and vascular leakage in isolated lungs. Role of the terminal complement sequence. Am. Rev. Respir. Dis. 139:88-99.

6. Langlois, P. F., and M. S. Gawryl. 1988. Accentuated formation of the terminal C 5b-9 complement complex in patient plasma precedes development of the adult respiratory distress syndrome. Am. Rev. Respir. Dis. 138:368-375.

7. Bariety, J., N. Hinglais, S. Bhakdi, C. Mandet, M. Rouchon, and M. Kazatchkine. 1989. Immunohistological study of complement $S$ protein (Vitronectin) in normal and diseased human kidneys: relationship to neoantigens of the C5b-9 terminal complex. Clin. Exp. Immunol. 75:76-81.

8. Falk, R. J., E. Podack, A. P. Dalmassio, and J. C. Jennette. 1987. Localization of S-protein and its relationship to the membrane attack complex of complement in renal tissue. Am. J. Pathol. 127:182-190.

9. Hugo, F., S. Kramer, and S. Bhakdi. 1987. Sensitive ELISA for quantitating the terminal membrane C5b-9 and fluid-phase SC5b-9 complex of human complement. J. Immunol. Methods. 99:243-251.

10. Dejana, E., S. Colella, G. Conforti, M. Abbadini, M. Gaboli, and P. C. Marchisio. 1988. Fibronectin and vitronectin regulate the organization of their respective Arg-Gly-Asp adhesion receptor in cultured human endothelial cells. $J$. Cell Biol. 107:1215-1223.

11. Preissner, K. T., E. Anders, J. Grulich-Henn, and J. Müller-Berghaus. 1988. Attachment of cultured human endothelial cells is promoted by specific association with $\mathrm{S}$ protein (vitronectin) as well as with the terminary $\mathrm{S}$ proteinthrombin-antithrombin III complex. Blood. 71:1581-1589.

12. Preissner, K. T. 1991. Structure and biological role of vitronectin. Annu. Rev. Cell Biol. 7:275-310.

13. Bhattacharya, J. 1988. Hydraulic conductivity of lung venules determined by split-drop technique. J. Appl. Physiol. 64:2562-2567.

14. Qiao, R.-L., and J. Bhattacharya. 1991. Segmental barrier properties of the pulmonary microvascular bed. J. Appl. Physiol. 71:2152-2159.

15. Baker, P. J., T. F. Lint, B. C. McLeod, C. L. Behrends, and H. Gewurz. 1975. Studies of the inhibition of C56-induced lysis ( reactive lysis) 4. Modulation of C56-induced lysis by polyanions and polycations. J. Immunol. 114:554-558.

16. Gawryl, M. S., M. T. Simon, J. L. Eatman, and T. F. Lint. 1986. An enzyme-linked immunoabsorbent assay for the quantitation of the terminal complement complex from cell membranes or in activated human sera. J. Immunol. Methods. 95:217-25.

17. Di Carlo, F. J., and J. V. Fiole. 1957. On the composition of zymosan. Science (Wash. DC). 127:756-757.

18. Podack, E. R., W. P. Kolb, and H. J. Müller-Eberhard. 1976. Purification of the sixth and seventh component of human complement without loss of hemolytic activity. J. Immunol. 116:263-269.
19. Chenais, F., G. Virella, C. C. Patrick, and H. H. Fudenberg. 1977. Isolation of soluble immune complexes by affinity chromatography using staphylococcal protein A-sepharose as substrate. J. Immunol. Methods. 18:183-192.

20. Doumas, B. T., D. D. Bayse, R. J. Carter, T. Petres, Jr., and R. Schafer. 1981. A candidate reference method for determination of total protein in serum. Clin. Chem. 27:1642-1650.

21. Williams, C. A., and M. W. Chase. 1977. Methods in immunology and immunochemistry. Academic Press, New York. Vol. IV. 137-153.

22. Bhattacharya, J., M. A. Gropper, and N. C. Staub. 1984. Interstitial fluid pressure gradient measured by micropuncture in excised dog lung. J. Appl. Physiol. 56:271-277.

23. Cheresh, D. A. 1987. Human endothelial cells synthesize and express an Arg-Gly-Asp-directed adhesion receptor involved in attachment to fibrinogen and von Willebrand factor. Proc. Natl. Acad. Sci. USA. 84:6471-6475.

24. Hugo, F., T. Hamdoch, D. Mathey, H. Schäfer, and S. Bhakdi. 1990. Quantitative measurement of SC $5 b-9$ and $\mathrm{C} 5 \mathrm{~b}-9(\mathrm{~m})$ in infarcted area of human myocardium. Clin. Exp. Immunol. 81:132-136.

25. Muller-Eberhard, H. J. 1986. The membrane attack complex of complement. Annu. Rev. Immunol. 4:503-528.

26. Suzuki, S., M. D. Pierschbacher, E. G. Hayman, K. Nguyen, Y. Ohgren, and E. Ruoslahti. 1984. Domain structure of vitronectin. J. Biol. Chem. 259:15307-15314.

27. Ruoslahti, E., and M. D. Pierschbacher. 1987. New perspectives in cell adhesion: RGD and integrins. Science (Wash. DC). 238:491-497.

28. Biesecker, G. 1990. The complement SC5b-9 complex mediates cell adhesion through a vitronectin receptor. J. Immunol. 145:209-214.

29. Albelda, S. M., and C. A. Buck. 1990. Integrins and other cell adhesion molecules. FASEB (Fed. Am. Soc. Exp. Biol.) J. 4:2868-2880.

30. Lampugnani, M. G., M. Resnati, E. Dejana, and P. C. Marchisio. 1991. The role of integrins in maintenance of endothelial monolayer integrity. J. Cell Biol. 112:479-90.

31. Bhakdi, S., F. Hugo, and J. Tranum-Jensen. 1990. Functions and relevance of the terminal complement sequence. Blut. 60:309-318.

32. Parsons, P. E., and P. C. Giclas. 1990. The terminal complement complex (SC5b-9) is not specifically associated with the development of the adult respiratory distress syndrome. Am. Rev. Respir. Dis. 141:98-103.

33. Gee, M. H., M. Margiotta, M. Tahamont, and J. T. Flynn. 1986. Free-radical generation in complement-induced pulmonary dysfunction. In Physiology of Oxygen Radicals. A. E. Taylor and S. Matalon, editors. American Physiological Society, Bethesda, MD. 187-216.

34. Till, G. O., K. J. Johnson, R. Kunkel, and P. A. Ward. 1982. Intravascular activation of complement and acute lung injury. J. Clin. Invest. 69:1126-1135.

35. Hogg, J. C. 1987. Neutrophil kinetics and lung injury. Physiol. Rev. 67:1249-1295.

36. Michel, C. C. 1984. Fluid movements through capillary walls. In Handbook of Physiology. S. R. Geiger, editor. Bethesda, MD. American Physiological Society, Bethesda, MD. Vol. IV, Chapter 9. 375-409.

37. Watson, P. 1984. Effect of plasma and red blood cells on water permeability of cat hindlimb. Am. J. Physiol. 246:H818-H823. 